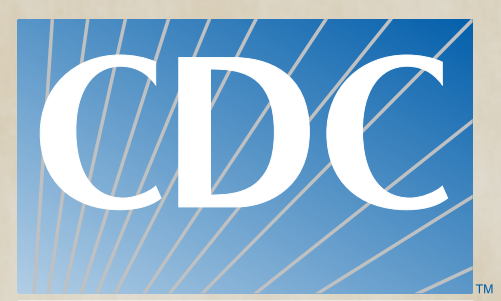

Workplace Safety and Health

\title{
Assessment of Noise Exposures in a Hospital Kitchen
}

Chandran Achutan, Ph.D.

Health Hazard Evaluation Report HETA 2007-0183-3047

Department of Veterans Affairs

Cincinnati, Ohio

August 2007

DEPARTMENT OF HEALTH AND HUMAN SERVICES

Centers for Disease Control and Prevention

Safety and Health 
The employer shall post a copy of this report for a period of $\mathbf{3 0}$ calendar days at or near the workplace(s) of affected employees. The employer shall take steps to insure that the posted determinations are not altered, defaced, or covered by other material during such period. [37 FR 23640, November 7, 1972, as amended at 45 FR 2653, January 14, 1980]. 


\section{CONTENTS}

\section{REPORT}

Abbreviations ....................................................................

Highlights of the NIOSH Health Hazard Evaluation............. iii

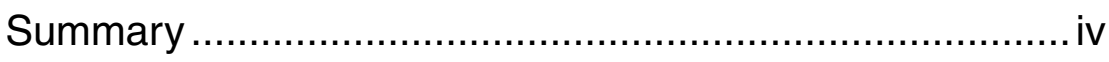

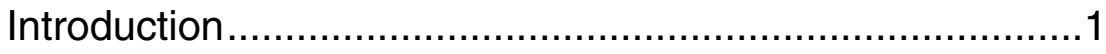

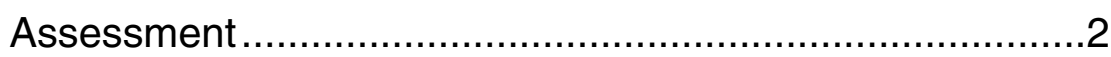

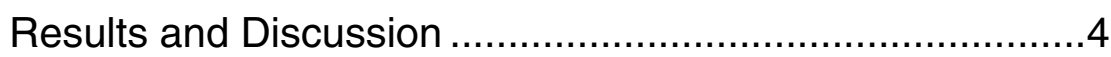

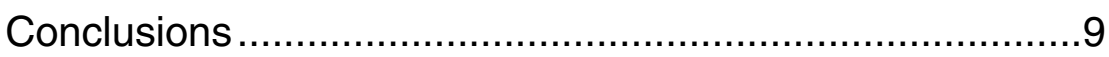

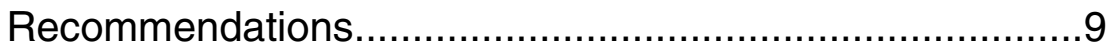

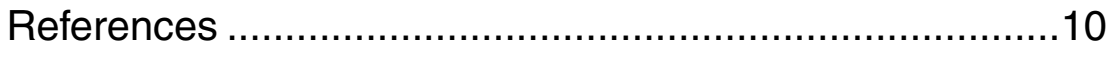




$\begin{array}{ll}\text { AL } & \text { Action level } \\ \text { CFR } & \text { Code of Federal Regulations } \\ \mathrm{dB} & \text { Decibels } \\ \mathrm{dBA} & \text { Decibels, A-weighted scale } \\ \mathrm{HHE} & \text { Health hazard evaluation } \\ \mathrm{HPD} & \text { Hearing protection devices } \\ \mathrm{Hz} & \text { Hertz } \\ \text { Leq } & \text { Equivalent continuous noise level } \\ \text { NAICS } & \text { North American Industry Classification System } \\ \text { NIHL } & \text { Noise-induced hearing loss } \\ \text { NIOSH } & \text { National Institute for Occupational Safety and Health } \\ \text { OSHA } & \text { Occupational Safety and Health Administration } \\ \text { PEL } & \text { Permissible exposure limit } \\ \text { REL } & \text { Recommended exposure limit } \\ \text { SLM } & \text { Sound level meter } \\ \text { TWA } & \text { Time-weighted average }\end{array}$




\section{HIG HUG HTS OF THE \\ NIOSH HEALTH \\ HaZARD Evaluation}

\section{What NIOSH Did}

- We measured full-shift and task-based noise levels for food service workers, cooks, and a materials handler.

- We took sound level measurements throughout the work area.

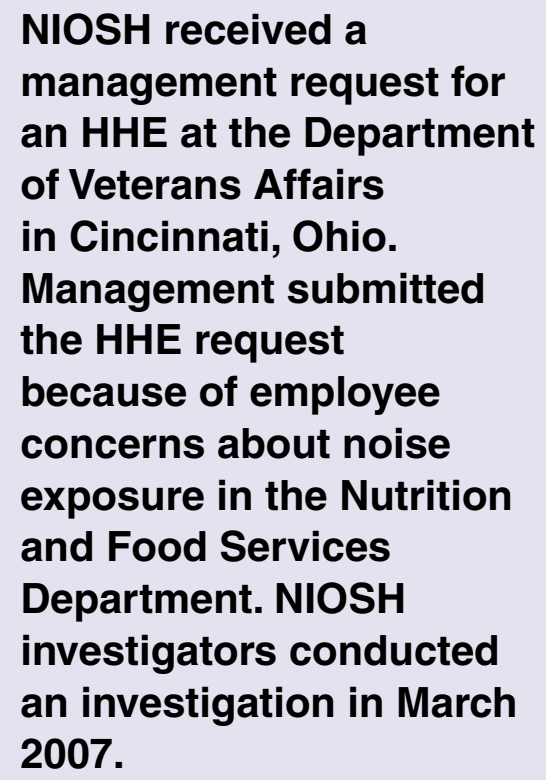

\section{What NIOSH Found}

- None of the employees exceeded the OSHA criteria for noise.

- Two employees working in the pots and pans room, a cook, and one employee working in the dishwashing room exceeded the NIOSH REL.

- A lot of the noise came from metal-to-metal contact between utensils and metal racks.

- The kitchen blenders and the pulper in the dishwashing room were very loud.

\section{What Department of Veterans Affairs Managers Can Do}

- Replace metal racks and utensils with non-metal food-safe materials.

- Replace the pulper with a garbage disposal system.

- Place blenders in noise-reduction enclosures.

- Conduct a noise survey after any engineering or administrative changes are made.

\section{What Department of Veterans Affairs Employees Can Do}

- Until noise exposures are reduced, wear HPD (ear plugs or ear muffs) in the dishwashing room. 


\section{Some employees in the hospital kitchen are exposed to excessive noise levels due to impact noise from metal-to- metal contact between utensils, between utensils and metal racks, and continuous noise from a waste-reduction machine. Noise exposures should be reduced through engineering and administrative controls.}

On March 21, 2007, NIOSH received a management request from the Industrial Hygiene and Safety Office at the Department of Veterans Affairs in Cincinnati, Ohio, to assess employee noise levels in the Nutrition and Food Services Department. The request stated that employees were concerned about noise exposures in the kitchen's pots and pans room after the installation of the PowerSoak ${ }^{\circledR}$, a continuous dishwashing system. On March 27-28, 2007, a NIOSH investigator evaluated employee exposures to noise in this department.

Eleven employees (two cooks, eight food service workers, and a materials handler) who worked in the Nutrition and Food Services Department contributed 13 full-shift and two task-based personal noise dosimetry measures over 2 days. None of the measures exceeded the OSHA criteria. Noise levels for two food service workers assigned to the pots and pans room, a cook working in the food preparation area, and a food service worker assigned to the dishwashing room exceeded the NIOSH REL. The noise level from the PowerSoak dishwashing system alone was not excessive, but additional noise from the food preparation area (primarily from blenders and utensils), and from metal-to-metal contact between stainless steel pots and pans and metal racks, may explain exposures above the NIOSH REL for the pots and pans room employees. The cooks are exposed to many intermittent impact noise sources from general handling such as metal-to-metal contact between utensils and the use of industrial-size blenders. The food service workers assigned to the dishwashing room are exposed to intermittent impact noise from contact between utensils and china, and continuous noise from the pulper, a waste-reduction machine.

Noise exposures to the cooks and the employees assigned to the pots and pans room should be lowered to maintain exposures below the NIOSH REL by reducing impact noise from metal-tometal contact between utensils and metal racks. In addition, the pulper should be replaced with a garbage disposal system to reduce noise exposures, and to prevent unsanitary work conditions from possible pulper malfunction.

Keywords: NAICS 622110 (General Medical and Surgical Hospitals), intermittent noise, impact noise, dose, kitchen, dishwasher, pulper, blenders, metal-to-metal contact. 


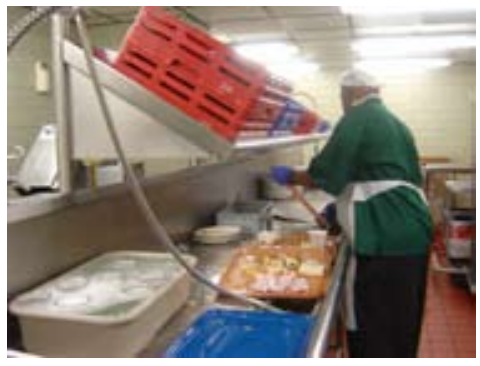

Photo1: Mechanical Dishwashing Table. The trays cover the table's drain. On the far left side of the photo is the pulper.
On March 21, 2007, NIOSH received a management request from the Industrial Hygiene and Safety Office at the Department of Veterans Affairs in Cincinnati, Ohio, to assess employee noise levels in the Nutrition and Food Services Department. The request stated that employees were concerned about noise exposures in the kitchen's pots and pans room after the installation of the PowerSoak ${ }^{\circledR}$, a continuous dishwashing system. On March 27-28, 2007, a NIOSH investigator conducted a noise assessment.

The Nutrition and Food Services Department prepares and provides meals to hospital inpatients. The department employs approximately 30 full-time and part-time food services workers, three cooks, and one materials handler. The full-time food service employees work from 6:00 a.m. to 2:30 p.m. or from 11:00 a.m. to 7:30 p.m., and the part-time employees work from 6:00 a.m. to $10: 00 \mathrm{a} . \mathrm{m}$. or from 3:30 p.m. to 7:30 p.m. The cooks work from 6:00 a.m. to 2:30 p.m. or from 8:00 a.m. to 4:30 p.m. The materials handler typically works from 8:00 a.m. to 4:30 p.m.

Meals are prepared by the cooks approximately 2-3 days in advance and stored in plastic storage containers in freezers. Work activities during meal preparation include slicing meat, opening food cans with a metal can opener, pureeing food in industrial-size blenders, and cooking. Ingredients and other materials needed for food preparation are transported by the materials handler on carts from freezers in the hospital basement. Every day, food service workers warm the pre-cooked meals, and place them on carts that are then transported to patient rooms. Diet aides, a job classification within food service workers, alert the staff preparing patient food carts when patients require special diets.

In the dishwashing room, one or two food service workers remove utensils (cups, plates, trays, and silverware) from carts and place them on a mechanical stainless steel dishwashing table. While the empty carts are being power-washed, leftover food from patient rooms is scraped from the plates and placed in a drain with running water that is part of the dishwashing table (Photo 1). This food/water mix is fed into a "pulper," a machine designed to reduce waste by removing the water and cutting up the dried food into small sizes. The pulper is attached to the dishwashing table. Except for the trays, utensils are placed in plastic racks or containers before they are placed in a dishwasher. The dishwasher washes, rinses, sanitizes, and dries the utensils, which are then put away by the food services workers. 


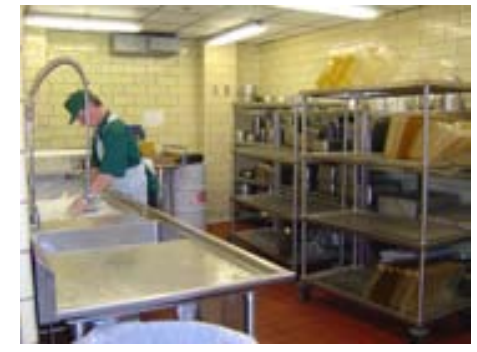

Photo 2: PowerSoak® Continuous

Dishwashing System. On the right side of the photo are metal pots and pans.
Oversized metal trays, pots, and pans that are used in food preparation, and plastic food storage containers, are cleaned in the pots and pans room using the PowerSoak continuous dishwashing system, and air-dried on metal racks in this room (Photo 2).
The objectives of this evaluation were as follows: (1) evaluate personal noise levels for employees in the kitchen area, (2) identify specific sources of loud noise, and (3) look for noise frequencies that cause NIHL.

Eleven employees (two cooks, eight food service workers, and a materials handler) contributed 13 full-shift and two task-based personal noise measures over 2 days. NoisePro ${ }^{\mathrm{TM}}$ noise dosimeters from Quest ${ }^{\circledR}$ Technologies (Oconomowoc, Wisconsin) were worn by the employees while they performed their daily activities. The noise dosimeters were attached to the wearer's belt and a small remote microphone was fastened to the wearer's shirt at a point midway between the ear and the outside of the shoulder. A windscreen provided by the manufacturer of the dosimeter was placed over the microphone during recordings. At the end of the sampling period, the dosimeter was removed and paused to stop data collection. The information stored in the dosimeters was downloaded to a personal computer for interpretation with QuestSuite ${ }^{\circledR}$ Professional II computer software. The dosimeters were calibrated before and after the measurement periods according to the manufacturer's instructions.

The Quest dosimeters collect data so that one can directly compare the information with the three different noise criteria used in this survey, the OSHA PEL and AL, and the NIOSH REL. The OSHA criteria use a $90 \mathrm{dBA}$ criterion and a $5-\mathrm{dB}$ exchange rate. The difference between the two is the threshold level employed, with a $90 \mathrm{dBA}$ threshold for the PEL and an $80 \mathrm{dBA}$ threshold for the AL. The threshold level is the lower limit of noise values included in the calculation of the criteria; values less than the threshold are ignored by the dosimeter 
The NIOSH criterion differs from OSHA in that the criterion is $85 \mathrm{dBA}$, the threshold is $80 \mathrm{dBA}$, and it uses a $3-\mathrm{dB}$ exchange rate. The dosimeters also allow a user-defined fourth criterion. For this evaluation the fourth criterion, designed to be a true Leq, was identical to the NIOSH criterion with the exception that the threshold level was set to OFF. This allowed for the integration of all sound levels including those below $80 \mathrm{~dB}$.

Table 1 summarizes the dosimeter settings used in this evaluation. Because of the different 8-hour criteria and exchange rates, the dose equations used to calculate the equivalent TWA values are different for the NIOSH and OSHA criteria.

The OSHA dose equation is

$$
T W A=16.61 \times \log _{10}[\text { Dose } / 100]+90,
$$

and the $\mathrm{NIOSH}$ equation is

$$
T W A=10.00 \times \log _{10}[\text { Dose } / 100]+85 .
$$

\begin{tabular}{lcccc}
\hline \multicolumn{5}{c}{ Table 1: Dosimeter Settings } \\
\hline Parameters & OSHA AL & OSHA PEL & NIOSH REL & Leq \\
\hline & & & & \\
Response & Slow & Slow & Slow & Slow \\
Exchange rate & 5 & 5 & 3 & 3 \\
Criterion level & 90 & 90 & 85 & 85 \\
Threshold & 80 & 90 & 80 & OFF \\
Upper limit & 115 & 115 & 115 & 115 \\
\hline \hline
\end{tabular}

Spot-checks of area noise levels and spectral analysis (breakdown of noise into different frequencies) were measured with a SoundPro ${ }^{\circledR}$ hand held SLM and real-time frequency analyzer. The instrument was set to measure noise levels between 70 and $140 \mathrm{dBA}$. The SLM was calibrated before and after the measurement periods according to the manufacturer's instructions. 
Information on the exposure limits for noise and its health effects is provided in the Appendix.

Table 2 shows the personal noise dosimetry results. None of the employees' levels exceeded the OSHA criteria for noise.

\begin{tabular}{|c|c|c|c|c|c|c|}
\hline \multirow[t]{2}{*}{ Area } & \multirow[t]{2}{*}{ Job Title } & \multirow{2}{*}{$\begin{array}{c}\text { Duration } \\
\text { (hours:minutes) }\end{array}$} & \multicolumn{4}{|c|}{${ }^{*}$ Percent Dose } \\
\hline & & & OSHA AL & OSHA PEL & NIOSH REL & Leq \\
\hline Pots and Pans Room & Food service worker & $03: 46$ & 23.7 & 14.3 & 102.8 & 105.1 \\
\hline Pots and Pans Room & Food service worker & $03: 35$ & 6.2 & 2.0 & 28.4 & 32.3 \\
\hline Pots and Pans Room & Food service worker & $08: 10$ & 30.1 & 10.9 & 102.2 & 111.4 \\
\hline Food Preparation & Food service worker & $08: 10$ & 6.7 & 1.2 & 18.8 & 26.2 \\
\hline Food Preparation & Food service worker & $01: 00$ & 3.6 & 1.4 & 12.2 & 13.2 \\
\hline Food Preparation & Food service worker & $08: 18$ & 18.8 & 6.1 & 55.9 & 62.7 \\
\hline Food Preparation & Food service worker & 09:07 & 11.6 & 3.0 & 32.5 & 38.3 \\
\hline Food Preparation & Food service worker & $10: 14$ & 7.2 & 2.1 & 28.8 & 34.9 \\
\hline Food Preparation & Cook & $08: 14$ & 27.0 & 8.0 & 84.7 & 91.9 \\
\hline Food Preparation & Cook & $08: 23$ & 28.1 & 10.0 & 84.8 & 92.8 \\
\hline Food Preparation & Cook & $08: 15$ & 33.9 & 16.5 & 119.5 & 126.0 \\
\hline Dishwashing Room & Food service worker & $04: 30$ & 27.6 & 18.8 & 151.9 & 154.4 \\
\hline Dishwashing Room & Food service worker & 04:03 & 4.7 & 1.4 & 14.8 & 17.5 \\
\hline All areas & Materials handler & $08: 11$ & 17.0 & 6.9 & 59.7 & 64.8 \\
\hline All areas & Materials handler & $08: 30$ & 14.2 & 4.6 & 43.2 & 49.2 \\
\hline
\end{tabular}

\footnotetext{
${ }^{*}$ The various dose percentages are the amounts of noise accumulated during a work day, with $100 \%$ representing the maximum allowable daily dose.
}

In the pots and pans room, noise levels for two food service workers exceeded the NIOSH REL. In addition, the level for a cook in the food preparation area also exceeded the NIOSH REL. The cook's exposure was $85.9 \mathrm{dBA}$, and the food service workers' exposures were 85.1 and $85.2 \mathrm{dBA}$ for the actual time worked. The noise exposures from the pots and pans room alone are not enough to explain employees' exposures exceeding the NIOSH REL.

The continuous noise level from the PowerSoak machine was 77 $\mathrm{dBA}$ and the noise levels from metal-to-metal contact between steel pans and racks, although high (80-90 dBA), were intermittent and short. The noise levels for various activities in the Nutrition and Food Services Department are provided in Table 3. The close proximity of the pots and pans room to the kitchen area suggests that the pots and pans room employees are exposed to noise from the kitchen area, primarily when cooking is in progress. Evidence of this is shown in Figures 1 and 2. In Figure 1, the noise exposure profile for a pots and pans employee is compared to that of a cook's working the same shift. The noise exposure profiles are similar. 


\section{RESULTS AND DISCUSSION \\ (CONTINUED)}

Table 3: Sound Level Measurements in the Hospital Kitchen

Area

Activity

Sound Levels (dBA)

Pots and Pans Room

$$
\begin{gathered}
\text { Pots and pans room, empty } \\
\text { PowerSoak machine ON, no employees } \\
\text { Radio and PowerSoak ON, by employee } \\
\text { When blenders on in kitchen, about } 15 \text { feet away } \\
\text { By radio, with PowerSoak ON } \\
\text { Metal-to-metal contact between steel pans and metal racks } \\
\text { Metal can opener } \\
\text { Compressor } \\
\text { Rolling carts on tiled floor } \\
\text { Ventilation system } \\
\text { Impact noise from metal spoon to metal container } \\
\text { Bag of frozen peas poured on stainless steel dish } \\
\text { Blenders ON }
\end{gathered}
$$

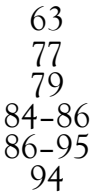

$69-81$

73

$77-80$

79

$85-92$

86
96

$72-81$

$80-83$

Power washing of food carts

Contact between plastic trays

Pulper ON; dishwashing table OFF

China-to-china contact

Pulper ON; dishwashing table ON

Figure 1: Comparison of Noise Exposures for a Cook and a Pots and Pans Room Employee

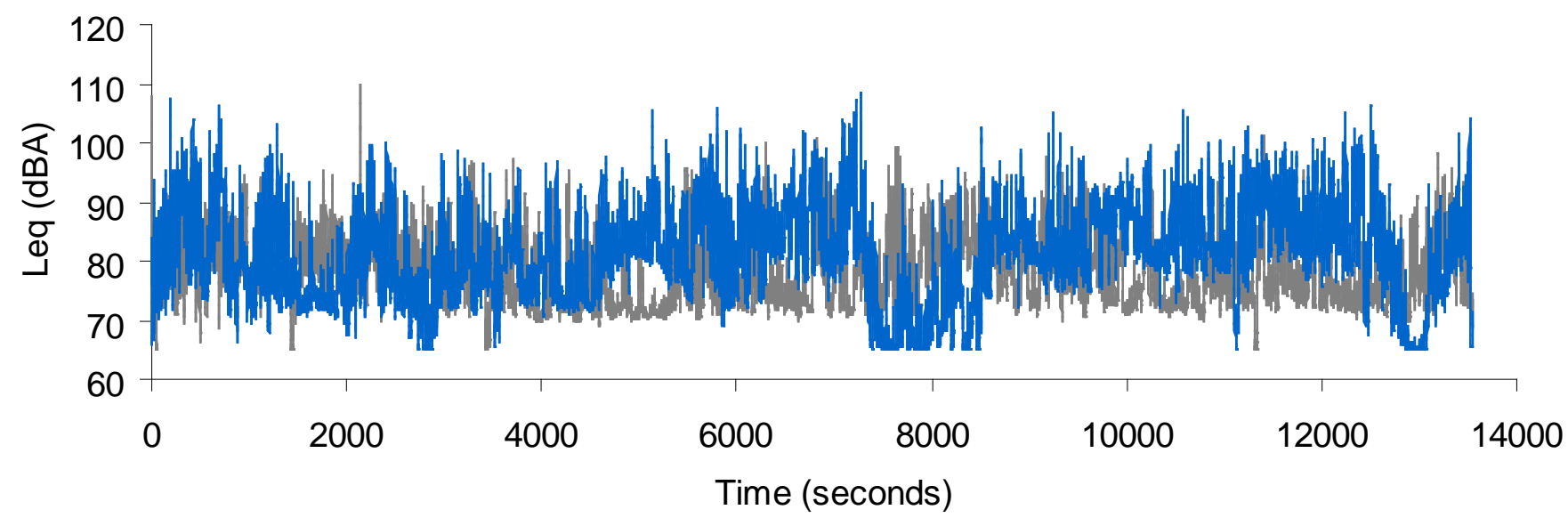

Cook-AM — Pots and Pans-AM 
In Figure 2, noise profiles for two part-time pots and pans employees are compared. One employee worked the morning shift (6:00 a.m. to 10:00 a.m.), and the other worked the evening shift (3:30 p.m. to 7:30 p.m.). The former had higher noise exposures that the latter. Cooking ceased at 2:30 p.m. on the days of the NIOSH evaluation.

Figure 2: Noise Exposures for Part-Time Pots and Pans Room Employees by Shift

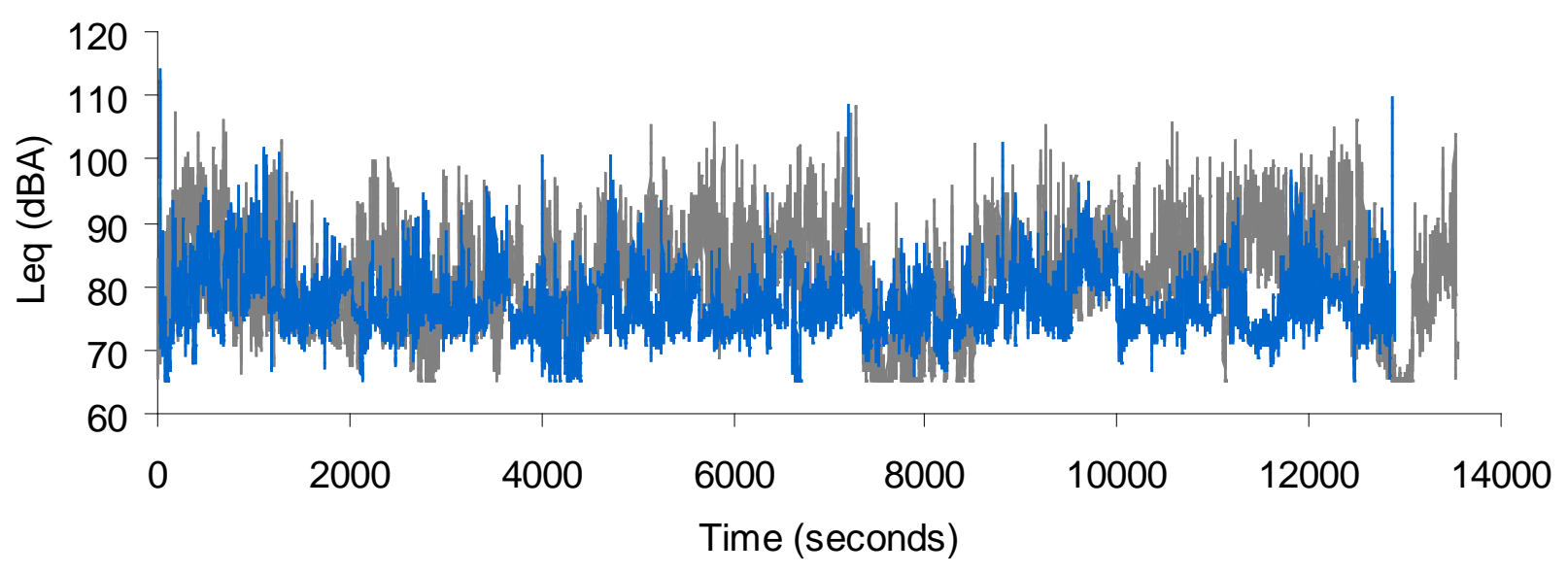

— Morning Shift — Evening Shift

Figure 3 compares the noise profiles of two part-time pots and pans employees with that of a full-time employee. The part-time employee' exposure profiles were similar to the full-time employee's for the comparable time that they worked in the pots and pans room. This suggests that employees working in the pots and pans room have uniform noise exposures.

Figure 3: Noise Exposures for Part-Time and Full-Time Employees in Pots and Pans Room

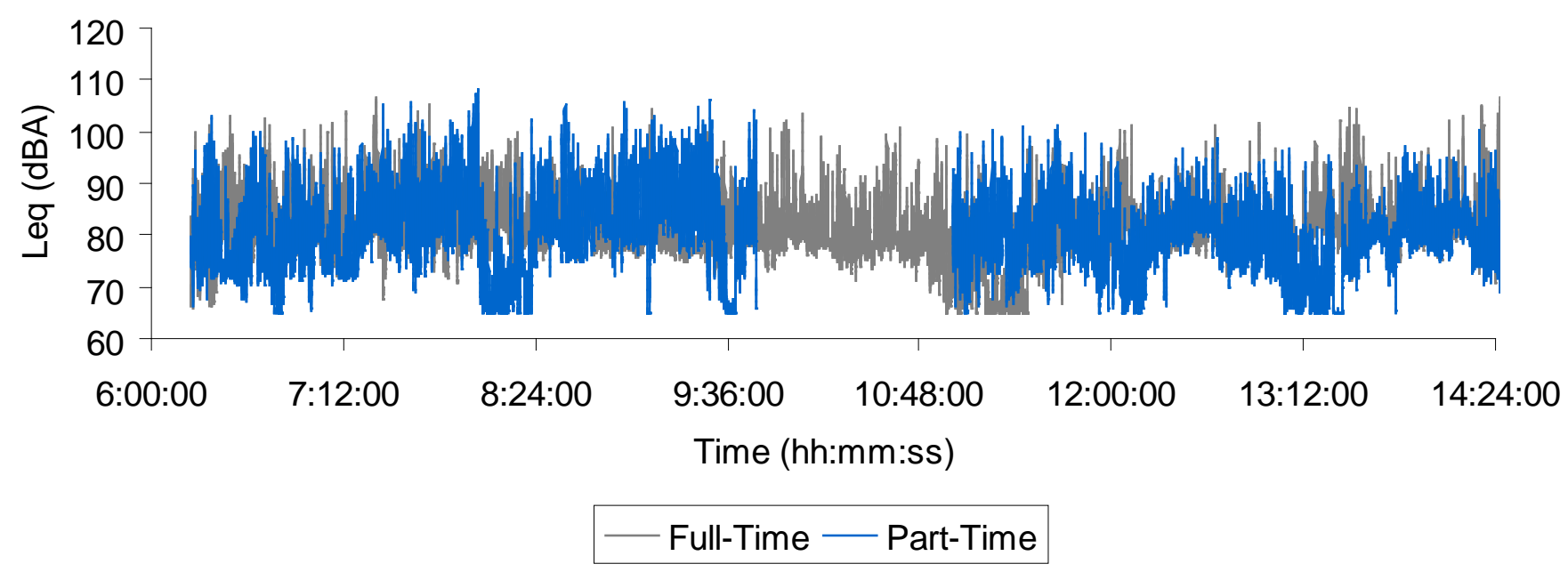


Two task-based personal dosimetry samples were taken in the dishwashing room. An employee who was unloading utensils from the carts and onto dishwashing racks had a 4-hour exposure of 89.5 dBA. He exceeded his daily allowable dose of $100 \%$ as determined by the NIOSH criterion. This employee's noise exposures came from the pulper (93 dBA), china-to-china contact (97 dBA), power washing of carts (80-83 dBA), and contact between utensils and the wash area $(85 \mathrm{dBA})$. An employee mentioned that the pulper often gets clogged and, during maintenance of the machine, it is common for the food/water mix to be strewn in the dishwashing room, creating an unsanitary situation.

Materials handlers and food service workers who are assigned as diet aides are unlikely to exceed any regulatory or recommended noise criteria. The materials handler does not spend long periods at any specific part of the Nutrition and Food Services Department. The diet aides spend most of their time in a fully enclosed office, with the doors closed. Spectral measurements, averaged over 60 seconds, were collected in the pots and pans room to determine frequencies at which the loudest exposures occur (Figure 4). The loudest exposures in the pots and pans room occurred at $315 \mathrm{~Hz}$. This frequency is not associated with NIHL, which usually occurs between $2000-6000 \mathrm{~Hz}$.

Figure 4: Spectral Data in Pots and Pans Room

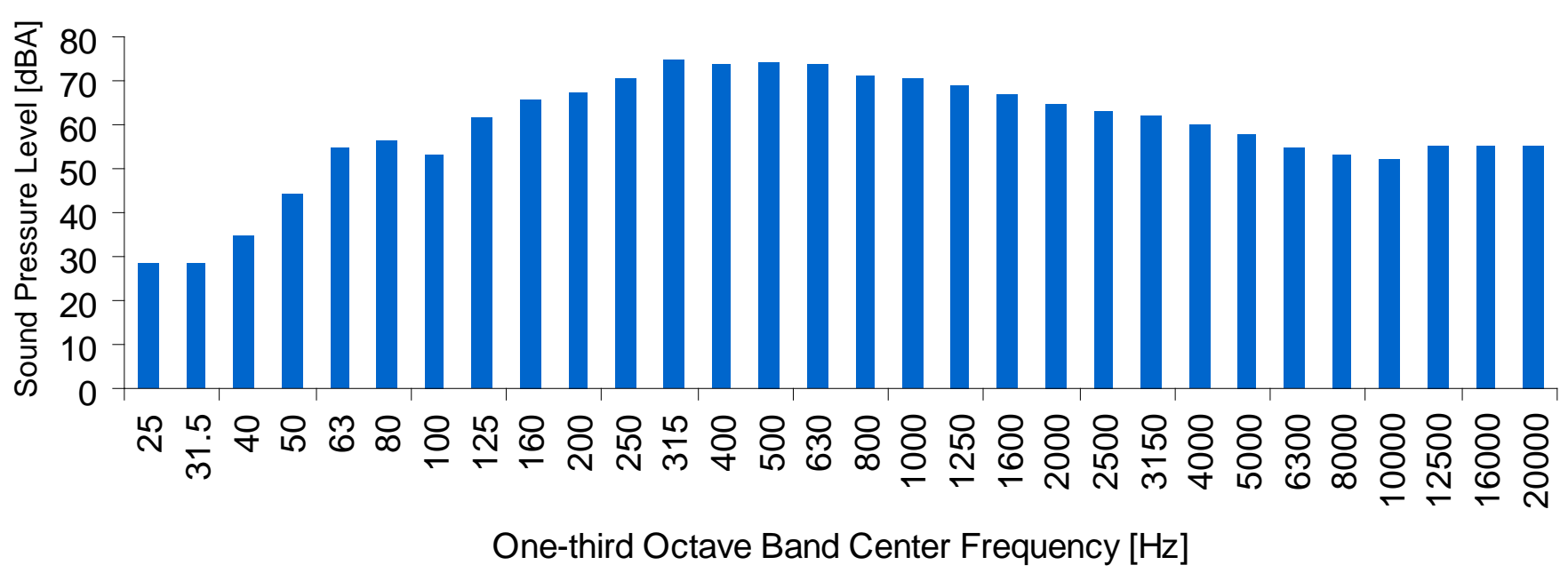

Pots and Pans Room 
Results AND Discussion (CONTINUED)

In the dishwashing room, spectral measurements were compared with the dishwashing table switched ON and switched OFF.

The pulper was on in both instances. The data, averaged over 20-40 seconds, are shown in Figure 5. As expected, noise levels are higher with the dishwashing table switched ON, but only at frequencies from $1250-20000 \mathrm{~Hz}$. At lower frequencies (less than $1000 \mathrm{~Hz}$ ), the average noise levels were higher with only the pulper switched ON. The maximum noise levels were 93.4 $\mathrm{dBA}$ with the dishwashing table switched OFF and $110 \mathrm{dBA}$ with the dishwashing table switched $\mathrm{ON}$. The frequencies associated with high noise levels with the dishwashing table switched OFF were 1250 and $1600 \mathrm{~Hz}$. The corresponding frequencies with the dishwashing table switched ON were between $2500-6300 \mathrm{~Hz}$, which is in the range where NIHL can occur.

Figure 5: Spectral Data in Dishwashing Room with Pulper ON

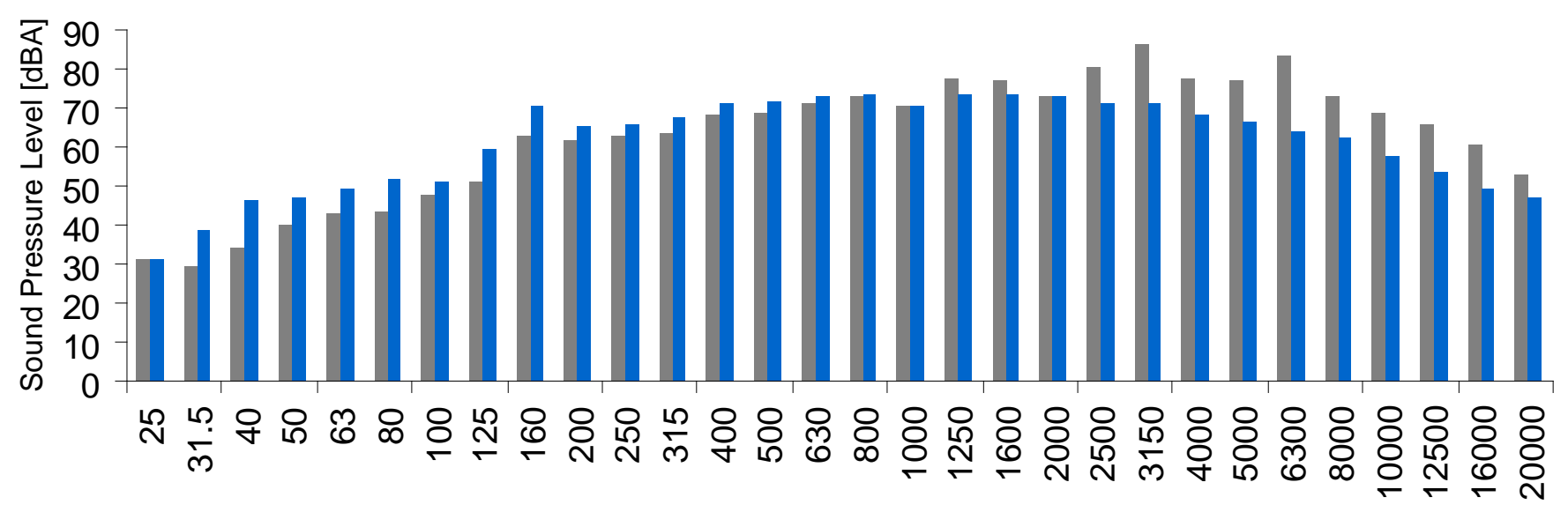

One-third Octave Band Center Frequency $[\mathrm{Hz}]$

Dishwashing Table ON $\square$ Dishwashing Table OFF 


\section{CONCLUSIONS}

Some employees in the Nutrition and Food Services Department are exposed to excessive noise levels. These employees include cooks and food service workers assigned to the pots and pans and dishwashing rooms. Food service workers who are assigned as diet aides and materials handlers are not likely to exceed any regulatory or recommended noise criteria.

\section{ReCOMmENDATIONS}

Based on the observations and findings of this evaluation, the following recommendations are offered to better protect the hearing of the employees in the Nutrition and Food Services Department. Engineering and administrative controls are the preferred ways of reducing workplace hazards.

1. Reduce metal-to-metal contact as much as possible. This can be accomplished by replacing metal racks with plastic racks, and replacing stainless steel utensils (e.g., ladles and tongs) with plastic materials. Make sure that the replacement products are food-safe.

2. Contact Waring®, the manufacturer of the kitchen blenders, to see if noise-reduction enclosures are available for the models used at the Nutrition and Food Services Department. Some commercial blenders manufactured by Waring provide noise-reduction enclosures. Otherwise, look into having noise-reduction enclosures made.

3. Replace the pulper in the dishwashing room with a garbage disposal system. This may reduce the noise exposure to the employees in addition to preventing unsanitary working conditions when the pulper becomes clogged.

4. Conduct personal noise dosimetry throughout the Nutrition and Food Services Department after any engineering, administrative, or process changes are made. If employee personal noise exposures continue to exceed the NIOSH REL, or if these changes cause employee exposures to exceed the OSHA AL, employees must be enrolled in a hearing conservation program. The basic elements of the program should, at a minimum, meet the requirements of the OSHA hearing conservation amendment [29 CFR 1910.95]. Other sources for defining effective hearing conservation programs are also available [Suter 2002; NIOSH 1996; Royster JD and Royster LH 1990].

5. Provide employees in the dishwashing room with HPD and training on proper use until engineering and administrative controls are in place. 
CFR. Code of Federal Regulations. Washington, DC: U.S. Government Printing Office, Office of the Federal Register.

NIOSH [1996]. Preventing occupational hearing loss-a practical guide. Cincinnati, OH: U.S. Department of Health and Human Services, Public Health Service, Centers for Disease Control and Prevention, National Institute for Occupational Safety and Health, DHHS (NIOSH) Publication No. 96-110.

Royster JD, Royster LH [1990]. Hearing conservation programs: practical guidelines for success. Chelsea, MI: Lewis Publishers.

Suter AH [2002]. Hearing conservation manual. $4^{\text {th }}$ ed. Milwaukee, WI: Council for Accreditation in Occupational Hearing Conservation. 


\section{Appendix: Evaluation Criteria}

The primary sources of evaluation criteria for noise in the workplace are: (1) the NIOSH REL [NIOSH 1992], and (2) the U.S. Department of Labor, OSHA PEL [29 CFR 1910.95]. Employers are encouraged to follow the more protective NIOSH REL, although they are required to adhere to the OSHA PEL for compliance purposes.

NIHL is an irreversible, sensorineural condition that progresses with exposure. Although hearing ability declines with age (presbycusis) in all populations, exposure to noise produces hearing loss greater than that resulting from the natural aging process. This noise-induced loss is caused by damage to nerve cells of the inner ear (cochlea) and, unlike some conductive hearing disorders, cannot be treated medically [Ward et al. 2000]. While loss of hearing may result from a single exposure to a very brief impulse noise or explosion, such traumatic losses are rare. In most cases, NIHL is insidious. Typically, it begins to develop at 4000 or $6000 \mathrm{~Hz}$ (the hearing range is $20 \mathrm{~Hz}$ to $20000 \mathrm{~Hz}$ ) and spreads to lower and higher frequencies. Often, material impairment has occurred before the condition is clearly recognized. Such impairment is usually severe enough to permanently affect a person's ability to hear and understand speech under everyday conditions. Although the primary frequencies of human speech range from $200 \mathrm{~Hz}$ to $2000 \mathrm{~Hz}$, research has shown that the consonant sounds, which enable people to distinguish words such as "fish" from "fist," have still higher frequency components [Suter 1978].

The $\mathrm{dBA}$ is the preferred unit for measuring sound levels to assess worker noise exposures. The dBA scale is weighted to approximate the sensory response of the human ear to sound frequencies near the threshold of hearing. The decibel unit is dimensionless, and represents the logarithmic relationship of the measured sound pressure level to an arbitrary reference sound pressure (20 micropascals, the normal threshold of human hearing at a frequency of $1000 \mathrm{~Hz}$ ). Decibel units are used because of the very large range of sound pressure levels which are audible to the human ear. Because the dBA scale is logarithmic, increases of 3 $\mathrm{dBA}, 10 \mathrm{dBA}$, and $20 \mathrm{dBA}$ represent a doubling, tenfold increase, and hundred-fold increase of sound energy, respectively. It should be noted that noise exposures expressed in decibels cannot be averaged by taking the simple arithmetic mean.

The OSHA standard for occupational exposure to noise specifies a maximum PEL of $90 \mathrm{dBA}$ for of 8 hours per day [29 CFR 1910.95]. The regulation, in calculating the PEL, uses a 5-dB time/intensity trading relationship, or exchange rate. This means that a person may be exposed to noise levels of $95 \mathrm{dBA}$ for no more than 4 hours, to $100 \mathrm{dBA}$ for 2 hours, etc. Conversely, up to 16 hours exposure to $85 \mathrm{dBA}$ is allowed by this exchange rate. The duration and sound level intensities can be combined in order to calculate a worker's daily noise dose according to the formula:

$$
\text { Dose }=100 \mathrm{X}\left(\mathrm{C}_{1} / \mathrm{T}_{1}+\mathrm{C}_{2} / \mathrm{T}_{2}+\ldots+\mathrm{C}_{\mathrm{n}} / \mathrm{T}_{\mathrm{n}}\right)
$$

where $C_{n}$ indicates the total time of exposure at a specific noise level and $T_{n}$ indicates the reference duration for that level as given in Table G-16a of the OSHA noise regulation. During any 24-hour period, a worker is allowed up to $100 \%$ of his daily noise dose. Doses greater than $100 \%$ exceed the OSHA PEL.

The OSHA regulation has an additional AL of $85 \mathrm{dBA}$; an employer shall administer a continuing, effective hearing conservation program when the 8-hour TWA value exceeds the AL. The program must 


\section{Appendix: Evaluation Criteria (continued)}

include monitoring, employee notification, observation, audiometric testing, HPD, training, and record keeping. All of these requirements are included in 29 CFR 1910.95, paragraphs (c) through (o). Finally, the OSHA noise standard states that when workers are exposed to noise levels in excess of the OSHA PEL of $90 \mathrm{dBA}$, feasible engineering or administrative controls shall be implemented to reduce the workers' exposure levels.

NIOSH, in its Criteria for a Recommended Standard, proposes an exposure criterion of $85 \mathrm{dBA}$ as a TWA for 8 hours, $5 \mathrm{~dB}$ less than the OSHA standard [NIOSH 1998]. The criterion also uses a more conservative $3 \mathrm{~dB}$ exchange rate in calculating exposure limits. Thus, a worker can be exposed to $85 \mathrm{dBA}$ for 8 hours, but to no more than $88 \mathrm{dBA}$ for 4 hours or $91 \mathrm{dBA}$ for 2 hours. The NIOSH REL for a 12 hour exposure is $83 \mathrm{dBA}$ or less.

\section{References}

CFR. Code of Federal Regulations. Washington, DC: U.S. Government Printing Office, Office of the Federal Register.

NIOSH [1992]. Recommendations for occupational safety and health: compendium of policy documents and statements. Cincinnati, OH: U.S. Department of Health and Human Services, Public Health Service, Centers for Disease Control and Prevention, National Institute for Occupational Safety and Health, DHHS (NIOSH) Publication No. 92-100.

NIOSH [1998]. Criteria for a recommended standard: occupational noise exposure (revised criteria 1998). Cincinnati, OH: U.S. Department of Health and Human Services, Public Health Service, Centers for Disease Control and Prevention, National Institute for Occupational Safety and Health, DHHS (NIOSH) Publication No. 98-126.

Suter AH [1978]. The ability of mildly hearing-impaired individuals to discriminate speech in noise. Washington, DC: U.S. Environmental Protection Agency, Joint EPA/USAF study, EPA 550/9-78-100, AMRL-TR-78-4.

Ward WD, Royster LH, Royster JD [2000]. Anatomy \& physiology of the ear: normal and damaged hearing. In: Berger EH, Royster LH, Royster JD, Driscoll DP, Layne M, eds. The noise manual. $5^{\text {th }}$ ed. Fairfax, VA: American Industrial Hygiene Association, pp 101-122. 
AND AVAILABIபTY OF The Hazard Evaluation and Technical Assistance Branch (HETAB) REPORT of the National Institute for Occupational Safety and Health (NIOSH) conducts field investigations of possible health hazards in the workplace. These investigations are conducted under the authority of Section 20(a)(6) of the Occupational Safety and Health (OSHA) Act of 1970, 29 U.S.C. 669(a)(6) which authorizes the Secretary of Health and Human Services, following a written request from any employers or authorized representative of employees, to determine whether any substance normally found in the place of employment has potentially toxic effects in such concentrations as used or found.

HETAB also provides, upon request, technical and consultative assistance to federal, state, and local agencies; labor; industry; and other groups or individuals to control occupational health hazards and to prevent related trauma and disease. Mention of company names or products does not constitute endorsement by NIOSH.

This report was prepared by Chandran Achutan of HETAB, Division of Surveillance, Hazard Evaluations and Field Studies (DSHEFS). Desktop publishing was performed by Robin Smith. Editorial assistance was provided by Ellen Galloway.

Copies of this report have been sent to employee and management representatives at the Department of Veterans Affairs and the OSHA Regional Office. This report is not copyrighted and may be freely reproduced. The report may be viewed and printed from the following internet address: http://www.cdc.gov/niosh/hhe. Copies may be purchased from the National Technical Information Service at 5825 Port Royal Road, Springfield, Virginia 22161. 
Recommended Citation: NIOSH [2007]. Health Hazard Evaluation Report: Assessment of Noise Exposures in a Hospital Kitchen, Department of Veterans Affairs, Cincinnati, Ohio. Cincinnati, OH: U.S. Department of Health and Human Services, Public Health Service, Centers for Disease Control and Prevention, National Institute for Occupational Safety and Health, NIOSH HETA No. 20070183-3047.

National Institute for Occupational Safety and Health

\section{Delivering on the Nation's promise: Safety and health at work for all people through research and prevention.}

To receive NIOSH documents or information about occupational safety and health topics contact NIOSH at:

1-800-35-NIOSH (1-800-356-4674)

Fax: 1-513-533-8573

E-mail: pubstaft@cdc.gov

or visit the NIOSH web site at:

http://www.cdc.gov/niosh/hhe 